
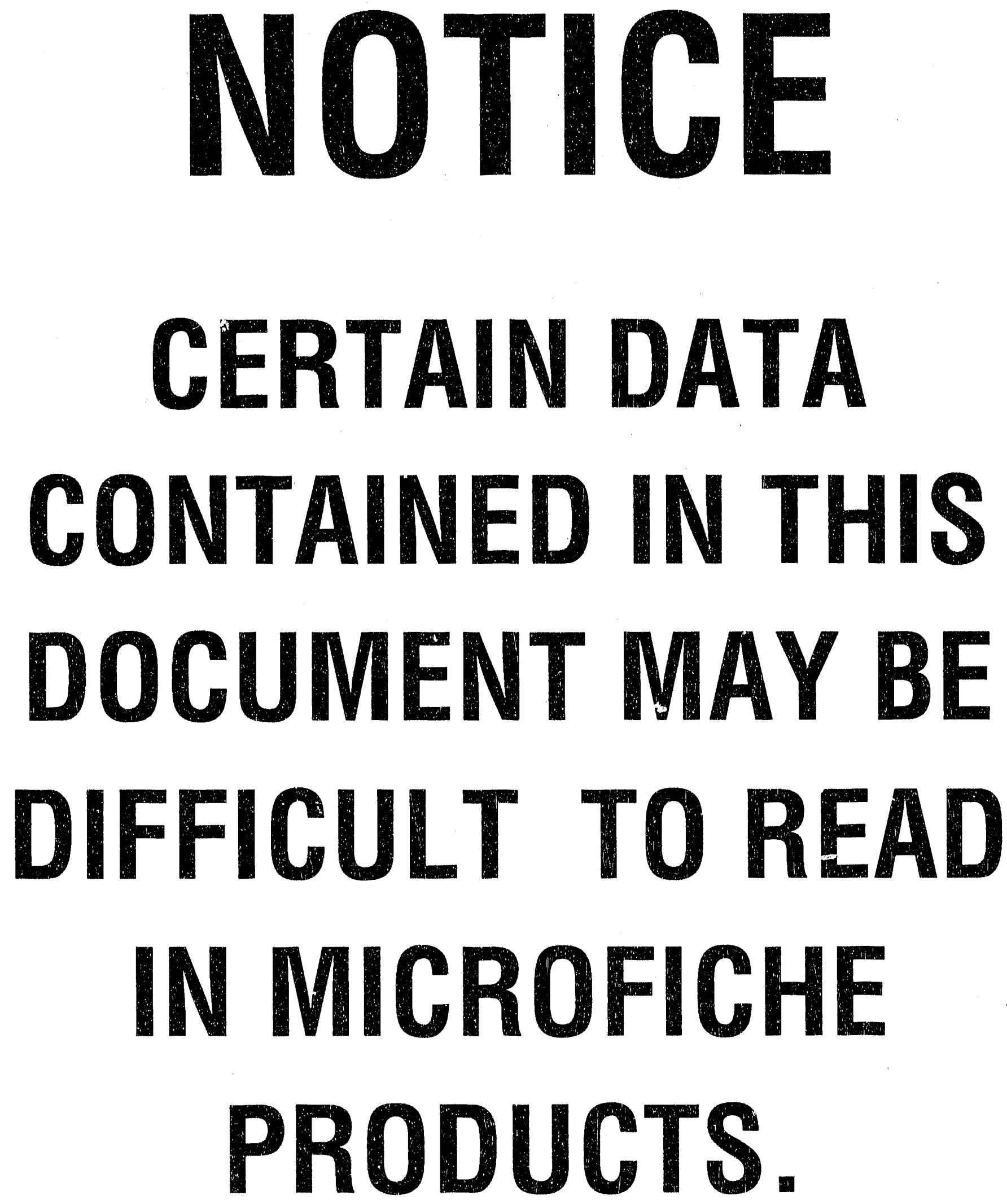


$$
\begin{gathered}
D E-F G 03-91 E R 61198 \text { DOE/ER/ } \\
A 001
\end{gathered}
$$

DOE/ER/61198--TI

DE92 013772

\title{
Arm Tropical Pacific Experiment (ATPEX): Role of Cloud, Water Vapor and Convection Feedbacks in the Coupled Ocean/Atmosphere System
}

\author{
V. Ramanathan \& T.P. Barnett \\ California Space Institute \& Climate Research Division \\ Scripps Institution of Oceanography, UCSD, La Jolla, CA 92093
}

Project Funded by Department of Energy, Office of Energy Research

Progress Report for the Period: September 1, 1991 - August 31, 1992

Report Date: March 5, 1992

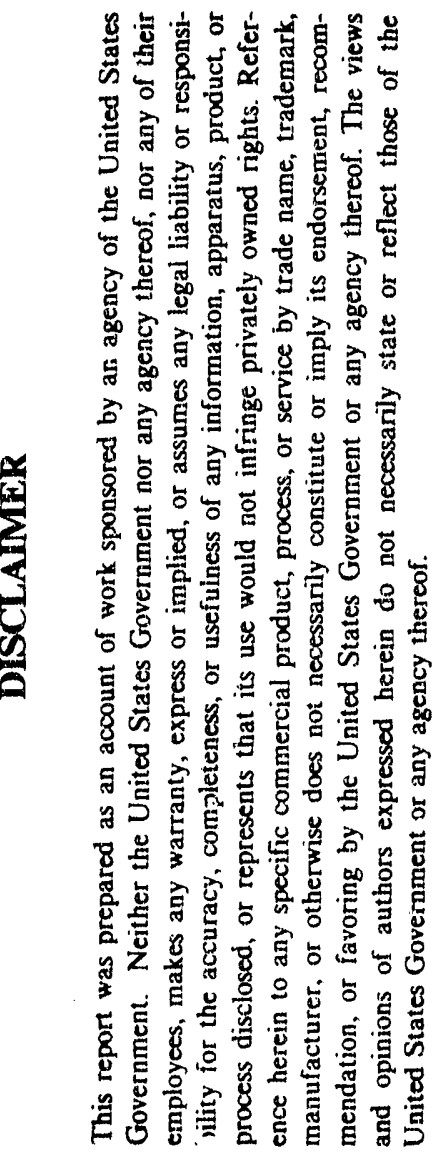

Table of Contents

1. Research Progress

(a) First Six Months

(b) Planned Studies for the Next Six Months

2. Papers Submitted

3. Personnel \& Status of Appointments

4. Equipment Purchases
Page Number

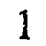

1

4

5

5

6

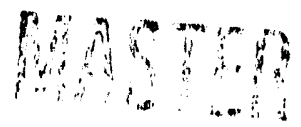




\section{RESEARCH PROGRESS}

(a) First Six Months:

During the first six months, we have created most of the infrastructure needed to integrate the ARM data with radiation models, AVHRR/ERBE satellite data, and GCMs. We have initiated studies that include radiation model validation, improved treatment of the three-dimensional structure of cloud-radiation interactions, and GCM sensitivity runs that will unravel the role of cloud-convection-radiation interactions in the Pacific SSTs and the overlying Walker and Hadley circulation.

As mentioned in the proposal (see p.10), the research program is divided into three phases. We are in Phase 1 which extends from Year 1 to Year 2. The specific scientific issues are subdivided into three categories (p.10): (i) Radiation; (ii) Cloud Parameterization Issues; (iii) Feedback and Ocean-Atmosphere Interactions. We will list the progress under each of these three categories.

(i) Radiation (J. del Corral, A. Inamdar \& V.R.amanathan):

The LOWTRAN 7 radiation code has been integrated with radiosonde soundings taken from ships over the tropical Pacific, Indian, and Atlantic oceans . A five-year data set from 1984 to 1989 has been assembled with a total of about 1500 soundings. This period was chosen because of the availability of the ERBE data set. We have computed the surface and top-of-the atmosphere fluxes, as well as flux divergences within the troposphere.

Role of Convection in the Atmospheric Greenhouse Effect: The computed atmospheric greenhouse effect $\left(G_{a}\right)$ from the soundings is in very good agreement with the ERBE data (Figure 1). In particular, the computed greenhouse effect simulates the super-greenhouse effect identified from ERBE data by Ramanathan \& Collins (1991, Nature, 351, p.27). Encouraged by this agreement, we are now analyzing the surface radiation flux and its relationship with sea surface temperature (SST) and the greenhouse effect. In particular, we are interested in the dependence of these processes on deep convection. Since one necessary condition for deep convection (Graham \& Barnett, 1987, Science, 238, p.657) is that SST should exceed about 300 $\mathrm{K}$, we separate the computed fluxes into two categories: (i) SST $>300 \mathrm{~K}$ to denote regions of convection; (ii) SST $<298 \mathrm{~K}$ to denote regions of no-convection. The averages of the greenhouse effect and the surface fluxes for the two regions (Figure 2) teveal several interesting features. The greenhouse effect and the downward emission are much larger in the convection regions. The entire troposphere contributes to the increase in $\mathrm{G}$, but roughly $70 \%$ of the increase comes from the increase in water vapor and lapse rate from surface to about $500 \mathrm{mb}$. It is also 
seen that water vapor increases rapidly in the boundary layer (1000 to $700 \mathrm{mb})$ up to a SST of about $300 \mathrm{~K}$. For SST $>3(\mathrm{~K}$ K $\mathrm{K}$, the boundary layer humidity is subject to considerable scatter and does not reveal a discernible trend wilh SST. For SST> $300 \mathrm{~K}$, the increase in vapor concentration is found mainly above the lxoundary layer.

The above results set the stage very nicely for our studies with the ARM site data over the western tropical Pacific. Since the radiosonde dalu are unreliable above pressure levels of about $500 \mathrm{mb}$, we are very keen on examining the link between convection, upper tropospheric water vapor and the greenhouse effect.

A paper on these results has been submilted for presentation at the AGU Spring 1992 Meeting.

(ii) Cloud Parameterization Lssues (I. Boer, JDC, \& VR):

Three-Dimensional Imaging of Clouds: We huve made substantial progress in the development of this tool. As proposed (p.1.3 of the proposill), we have incorporated the following features in a three-dimensional cloud imager, which employs the full resolution (1 km x $1 \mathrm{~km})$ AVHRR data :

- Clear-sky Identification: As a first guess, we employ the Coakley/Bretherton spatial coherence scheme on the IR window chummel. We then examine the ratio of the radiances of the two visible channels. One of these channcls is in the blue end of the spectrum (Channel 1), while the other is near the red end (Channel 2). Since the clear sky is blue and cloudy sky is white, the ratio of these two channels should be: much lurger for the clear-sky than for the cloudy sky. We use this property to filter out the clear scenes from the pixels chosen by the spatial coherence method.

- Optical Depth Detemination: We llien employ a delta-eddington multiple scattering code to solve for the optical depth of clouly pixc:ls, assuming that they fill the field of view.

- Edge Detection: A Delect and Spremal (DAS) method has been developed to label each cloud element within the scene. DAS first sickects a pixel with large optical depth, and then spreads this cloud all around until il concounlers a clear scene. An optically thin pixel attached to a thick cloud is assumed to have the same allinule as the thick cloud.

Many details of this cloud retricval and inmging algorithms are currently being documented in a report. An image of a cloud system in the mopicul Pacific, as reconstructed by the cloud imager is attached herewith (Figure 3). The immger revenls realistic structure of deep convective clouds and 
anvils. However, many serious problems remain which can only be resolved with in-situ data from the A $A$.M sites.

(iii) Feedback and Occun-Almusphure Interactions: (T.P. Barnett, M. Meyer, U. Schlese (MPI), JDC, \& VR):

\section{Atmosphere GCM :}

The Max-Planck Institute has given their latest version of the GCM, the T42 ECHAM3 version, for our studies. MM \& TPB have started a 14 year integration with observed SSTs for the period 1970-83; the ten years before AMIP, plus four overlap years. Lack of computer time will slow the progress of this run. This eventually will give us 20 years of T42 results, enough to do a decent statistical comparison with olsservalions.

Greenhouse Effecland Cloud Forcimg Results: Tom Peterson (a visitor from CSU) and TPB compared a reduced resolution version of ECL HAM3 simulated cloud and radiation variability over 1979-85 with satellite data. The model did remarkably well, and a paper describing the results has been submitted. MM, JDC, and VR have begun to compare the T42 model run for the 1980s with observed ERBE data. We are fixusing on the tropical Pacific oceans. The model is able to capture the gross features of the ohserved data. For example, it simulates the supergreenhouse effect over the convective regions and captures the near cancellation of the longwave and shortwave cloud forcing. However, the extreme values of the cloud-radiative forcing parameters are much larger in the model.

Radiative Effects of the 1987 Lil-Nino (MM, JDC \& VR): A more critical test of the model is the effect of the El-Nino on the radialive fluxes as identified in the Ramanathan \& Collins (1991) paper. The model is quile successful in simulating the increases in the greenhouse effect, the longwave and shortwave cloud forcing over the warmer central Pacific. The monthly mean differences shown in Figure 4 shows a remarkible similarity with the observed changes (compare Figures $4 \mathrm{a} \& 4 \mathrm{~b}$ ). The spatial distribution of radiation and greenhouse effects is also surprisingly well reproduced (compare Figures $5 a \& 5$ b). llowever, the magnitude of the cloud forcing changes are larger in the model (note the scule difference of the extreme in Figure 5). What is the significanct of this agreement? First, note that the warming in the central Pacific is accompanied ty deep convection, which in turn modifics the water vapor distribution and cirrus clouds. Since the altered water vapor distribution changes the greenhouse effect, the agreement with the observed changes in the greenhousc effecl and cloud forcing suggests that the model may have a realistic treatment of the coupling |x:lween convection, water vapor distribution, and cloudiness. 
This is certainly an encouraging beginning and comparison with the ARM surface data is the next step.

Cloud-Radiation Experiments (MM, VR, US): Motivated by the success of the model in simulating the El-Nino changes, we have lxegun cloud-radiation sensitivity experiments. A preliminary 60-day run has been completed, in which we are examining the importance of cirrusradiative forcing to the atmospheric dynamics and convection. By the end of Year-1, we would have completed several sensitivity studies, which will improve our understanding of the feedback effects of western Pacific cirrus clouds on the Walker and Hadley cell circulation.

Tropical Ocean GCM (TPB, A. Miller, J. Ritchie, \& N. Schneider (from May 1)): Jack Ritchie has spun up a new version of the OPYC (MPI OGCM), and is now testing it to see how well it did the seasonal cycle. Results to data are moderately encouraging, although the model does have some flaws. In addition, 1 16-year run with observed winds has just been completed. We are just stitring to study this run to see how well OPYC simulates natural variability. First indications are that the responses are too weak, but this may be due to a stronger than necessary empirical damping, which could be easily corrected. We have received a new MPI ocean model, which is a more conventional z-coordinate model with better numerics and a somewhat improved vertical mixing schemc. We are just starting to test it as an alternative to OPYC.

\section{(b) Planned Studies for the Second Six Months:}

Further work on the infrastructure (i) John del Corral will contact the ARM data group to acquire the data that will soon be collected at the first site in Oklahoma. The data that we need include surface and satellite (AVHRR) dati. We will automate the process of acquiring the data, computation of radiation flux, imaging of the three-dimensional cloud structure and validation, and tuning of the computed three-dimensional cloud and radiation fields; (ii) JDC will work with M. Meyer (GCM programmer) to develop) sin interactive image processing system to analyze the three-dimensional time evolution of ARM wnul CBCM fields.

Scientific Studies: (i) We will undertake comparison studies of ARM data with model fields. (ii) Preliminary estimates will be made of the non-linear relationship between sub-grid scale cloud properties and the averaged GCM sciale rindiation fields. (iii) We will complete our studies on the interactuon between convection, willer vilpur, and the greenhouse effect with the ship data. (iv) We will complete about 6 AGCM sunsitivily studies in which we systematically strip the model of cirrus clouds in various regions of the tropics to understand the planetary scale waves and motion 
fields forced by the cirrus radiative forcing. (v) The two ocean models will be inter-compared, and the best one retained for profuction work. (vi) N. Schneider will work to improve the vertical mixing process in the selected moklel, concentrating on performance in the warm pool. (vii) Various ENSO/non-ENSO simulinions will be carried out to determine the interaction of radiation and ocean mixing processises.

\section{Puvers Submitted}

E. Boer \& V. Ramanathan, 1992: Three-dimensional imaging of cloud structure using satellite radiances: a new tool for cloud studies. Suhmilled 10: All-Union Session on Scientific Visualization, AGU Joint Spring Meeting, Montrenl, Canada, May 12th-15th.

A.K. Inamdar \& V. Ramanathan, 19)2: More on the water vapor greenhouse effect over the tropical oceans. AGU Joint Spring Meeting, Montreal, Canada, May 12th-15th.

T.C. Peterson, T.P. Barnett, E. Roeckner, \& T.H. Vonder Haar, 1992: An analysis of the relationship between cloud anomalies and sen surface temperature anomalies in a global circulation model. Submitted to: Journal of (jeophysicul Research - Atmospheres.

\section{Persomel \& Stailus of Appointment}

We list below the research personnel whose suluries are currently paid by this proposal:

(i) Programmers:
Mi. Meyer:
$1(x) \%$
J. del Corral:
$50 \%$
J. Ritchie:
$5(1) \%$

(ii) Scientists:
A. Miller
$2.5 \%$
A.K. Inamdar:
.5()$\%$

(iii) New Appoimuments: We propused to hire three new research scientists by the end of three months after getting the grunt (i.e., hy 1 xecember 1st). Because of changes in appointment policies, there has been sonk delays. A posi-doctoral Oceanngrapher, Dr. N. Schneider will join 
us by May 1st to work on problems dealing with the vertical mixing parameterization in ocean models. We have selected a short list of candidates for the two atmospheric science positions, and hope to have them on-board by June 1st. In the meantime, Dr. Inamdar (a post-doc) wrill work on radiation model studies in the western Pacific region. E. Boer, an imaging specialist, will complete work on the three- dimensional cloud imager. We have received approval from DOE to use a portion of the unused funds for buying urgently and badiy needed computing equipment, the details of which are given next.

\section{Equipment Purchases}

ARM \& Satellite Data Studies: We have ordered a high capacity erasable opticall automated removable media mass storage system. This system includes disk drives and media for 60 Gigabytes of storage, a high performance workstation front-end, and a 5 Gigabyte $8 \mathrm{~mm}$ tape drive. The workstation (SPARC 2) will run database software to manage and retrieve the data stored cn optical disks and also provide network access to the data. The data stored on this system will include the ARM data set, AVHRR, and ERBE satellite images, field measurements, and GCM model results.

The total cost of the system is $\$ 102,780$, and was cost-shared by $\$ 35,000$ from DOE funds, with the balance from ERBE and CERES grants and $\$ 40,000$ seed funds from the NSF Science and Technology Center for Clouds, Chemistry, and Climate. As soon as this system arrives (by midMarch), JDC will integrate the system into our facility for analy sis of satellite data and model results (Figure 6).

GCM Studies: A disk farm system has been ordered, consisting of a server and 14 Gigabytes of on-line storage. This will accommodate the AGCM history files and sensitivity runs, as well as to provide rapid data access for real-time graphics work. We plan to mate this system with the optical jukebox system during Year 2. 


\section{SHIP DATA LOCATIONS 1985 - 89}
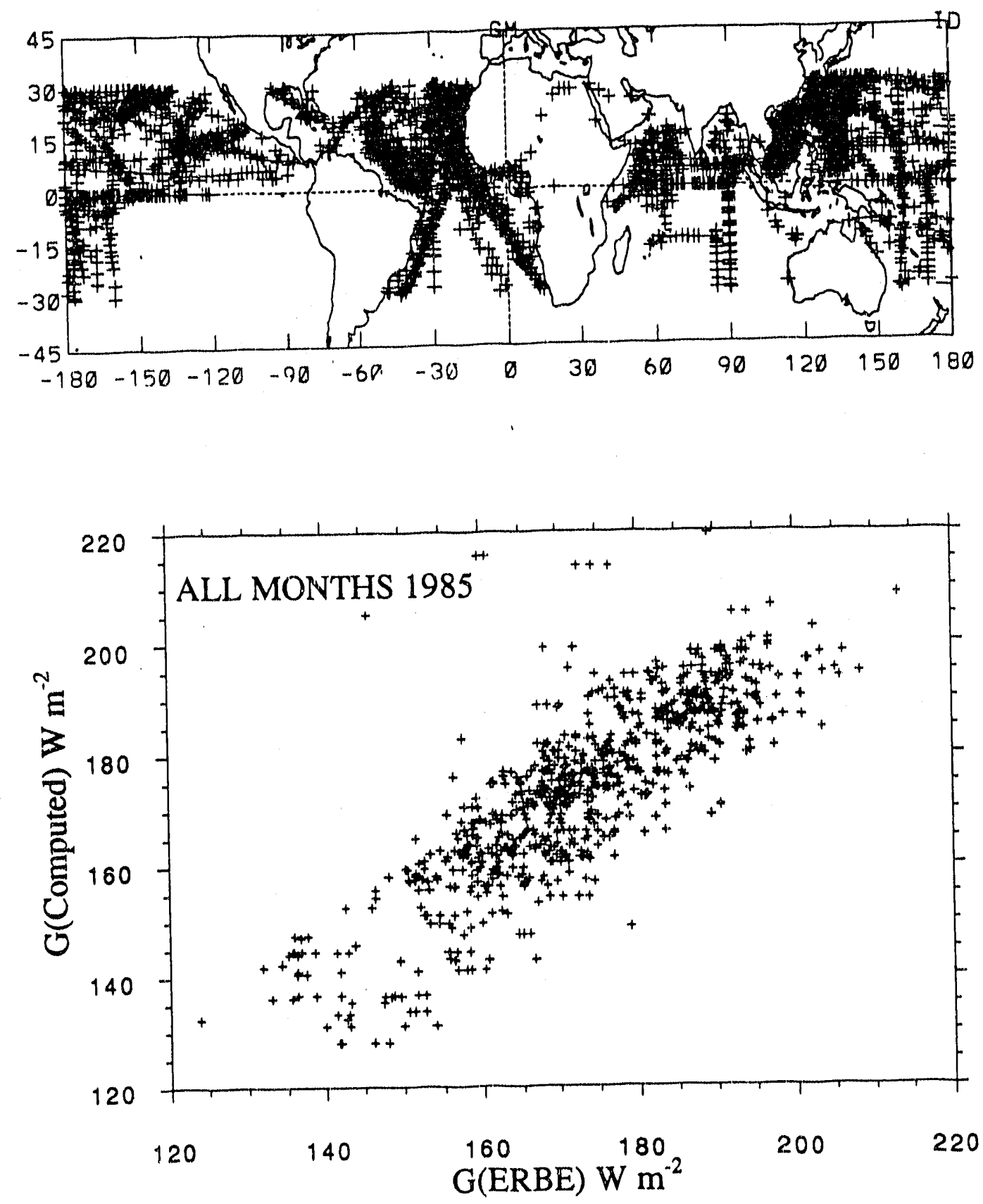

FIGURE 1: Top panel shows the location of ship sondes used in the radiation model study. Bottom parels shows a comparison of observed atmospheric greenhouse effect with computed values for co-located regions and times. The computed values are obtained from the radiosonde soundings obtained from the ship observations. 
"Non-Convective Region"

$(292$ - $298 \mathrm{~K})$
"Convective Region"

$(>300 \mathrm{~K}$ )
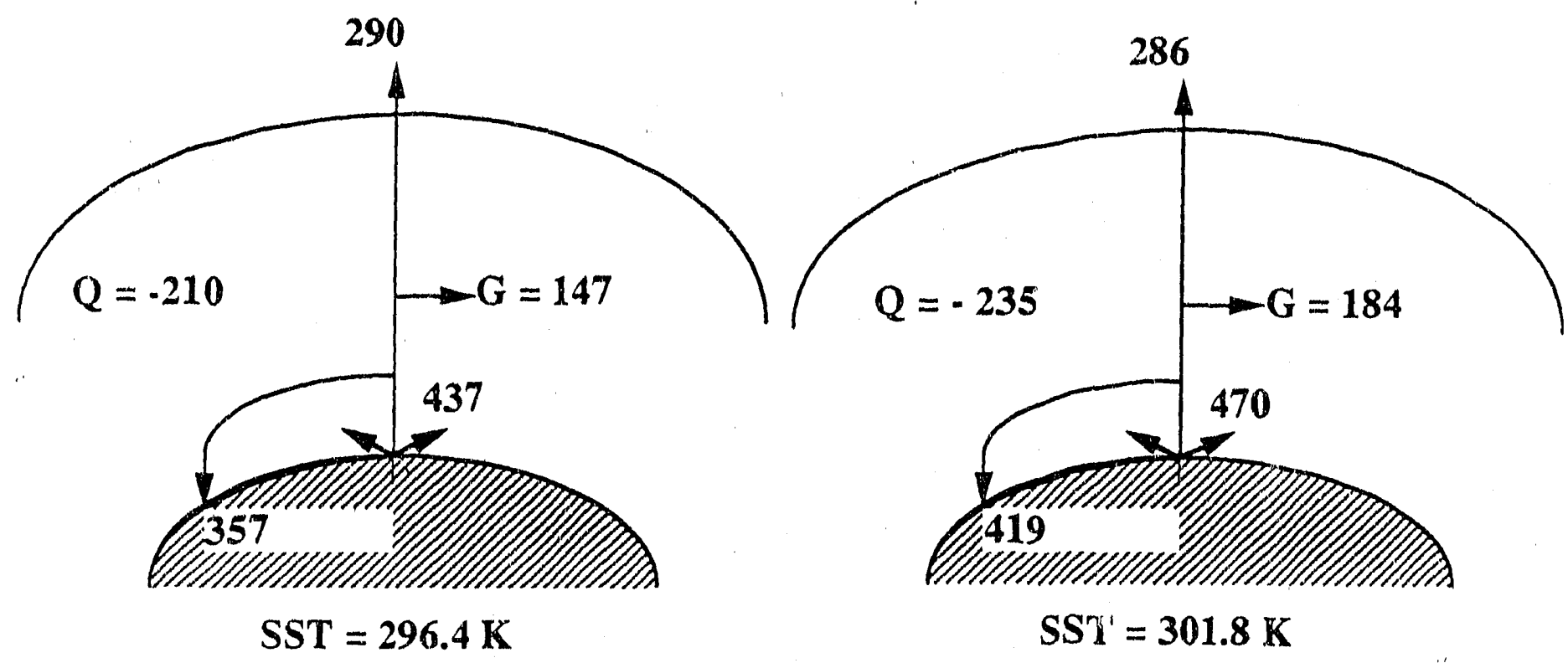

$\mathrm{SST}{ }^{\prime}=301.8 \mathrm{~K}$
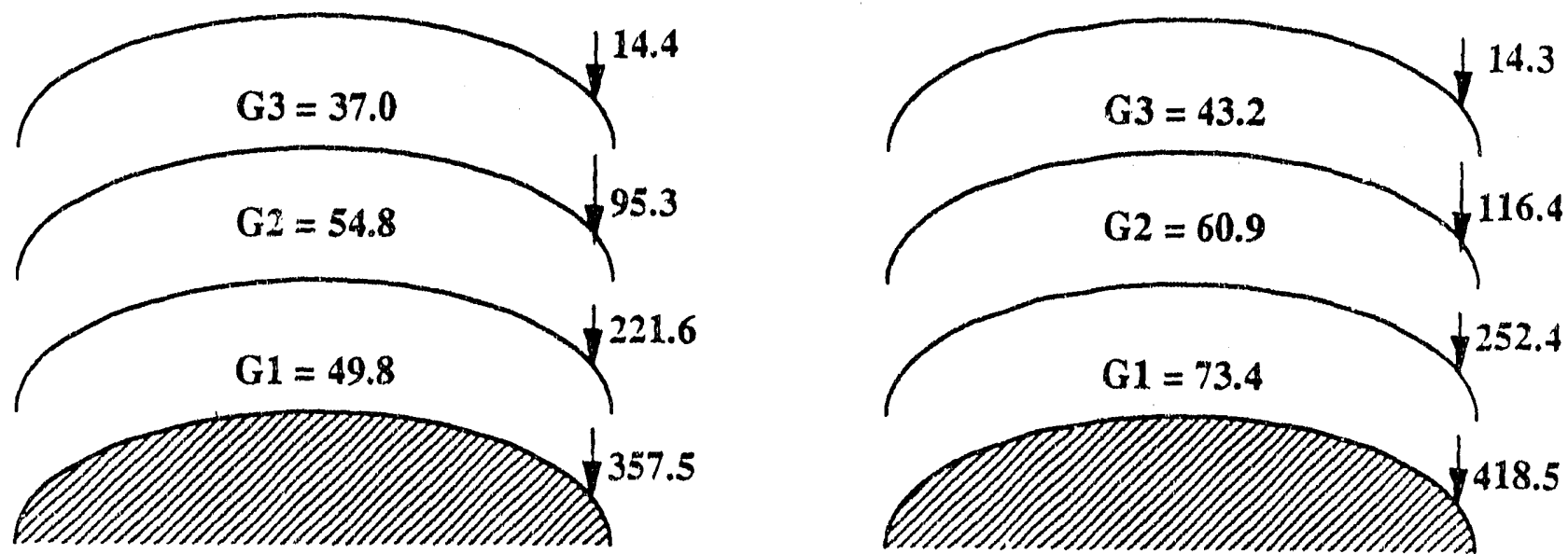

FI GURE 2:

Global longwave energy budgets for the non-convective and convective regimes. $G$ is the total greenhouse trapping in the atmosphere, $\mathrm{Q}$ is the radiative cooling of the entire atmospheric column. G1, G2 and G3 in the lower half of the figure refer to the greenhouse trapping in the lower, middle and upper tropospheres respectively. The downward fluxes at the boundaries of these layers are shown to the right. All energy units are in $\mathrm{W} / \mathrm{m}^{\wedge} 2$. 
FIGURE 3: Three-dimensional reconstruction of clouds from AVHRR image of a convectivecirrus scene in the Pacific. Cloud properties are obtained from the two visible and two IR window channels. The top and bottom images show two different $150 \mathrm{~km} \mathrm{x}$ $75 \mathrm{~km}$ regions. The ruler on the bottom image shows the height scale. The top of the red marker is $20 \mathrm{~km}$ in altitude. The scene is viewed from an altitude of about 16 $\mathrm{km}$ for the top image and from $32 \mathrm{~km}$ for the bottom image. Both reveal deep convective cloud clusters with extended anvil cirrus clouds with the base at about 10 km. Source: E. Boer \& V. Ramanathan (1992). 


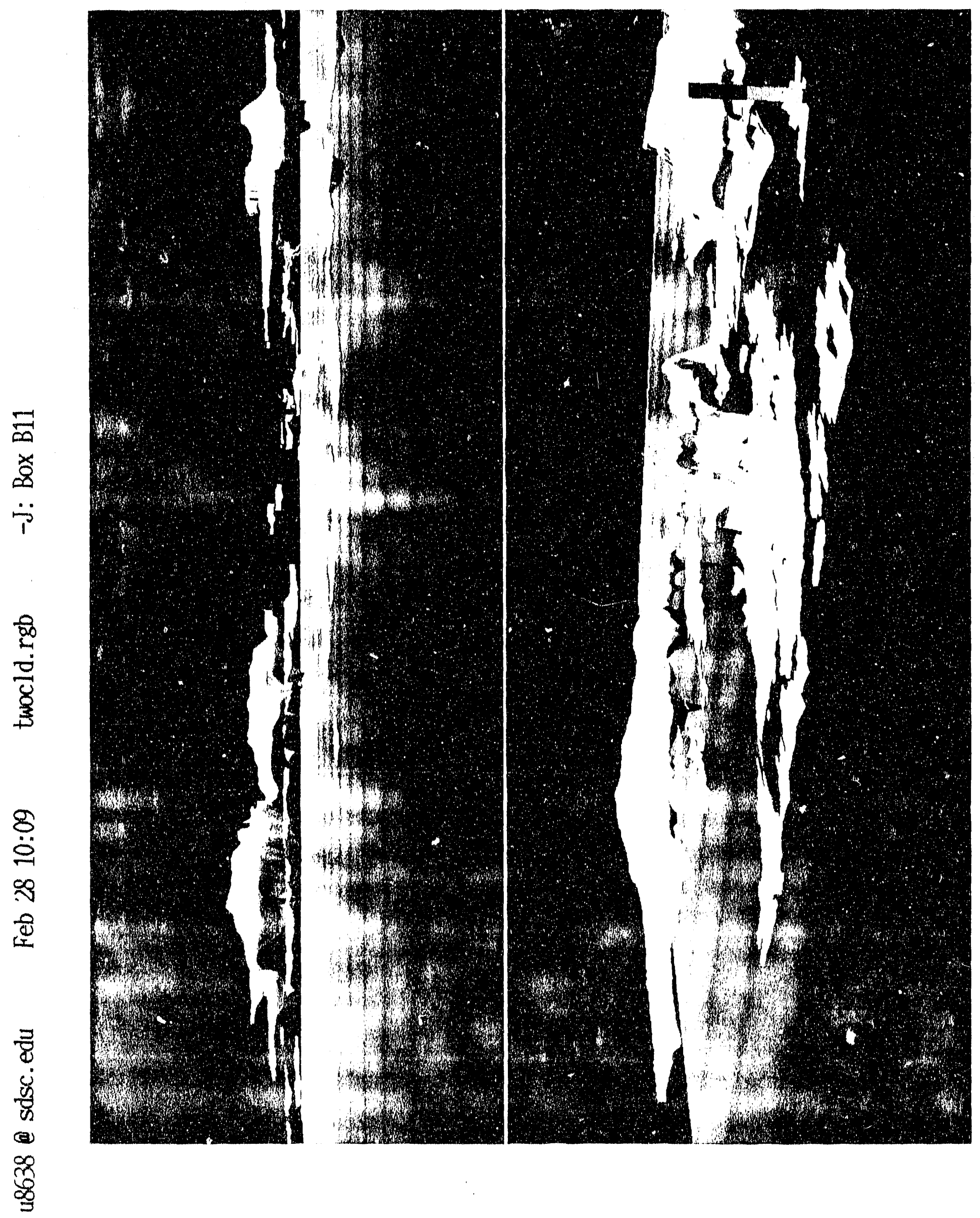


FIGURE 4: Comparison of the simulated greenhouse effect and cloud forcing with ERBE results.

Figure 4a: ERBE results for the tropical Pacific as shown in Ramanathan and Collins (1991). Top leit parel shows, $\mathrm{G}$, the greenhouse effect of the atmosphere and clouds plotted against SST. Top right panel shows $\mathrm{G}_{\mathrm{a}}$, the greenhouse effect of just the atmosphere plotted against SST. Bottom left panel shows a scatter plot of shortwave cloud forcing against longwave cloud forcing.

Figure 4b: Same as Figure 4a, but for computed fields by ECHAM. 

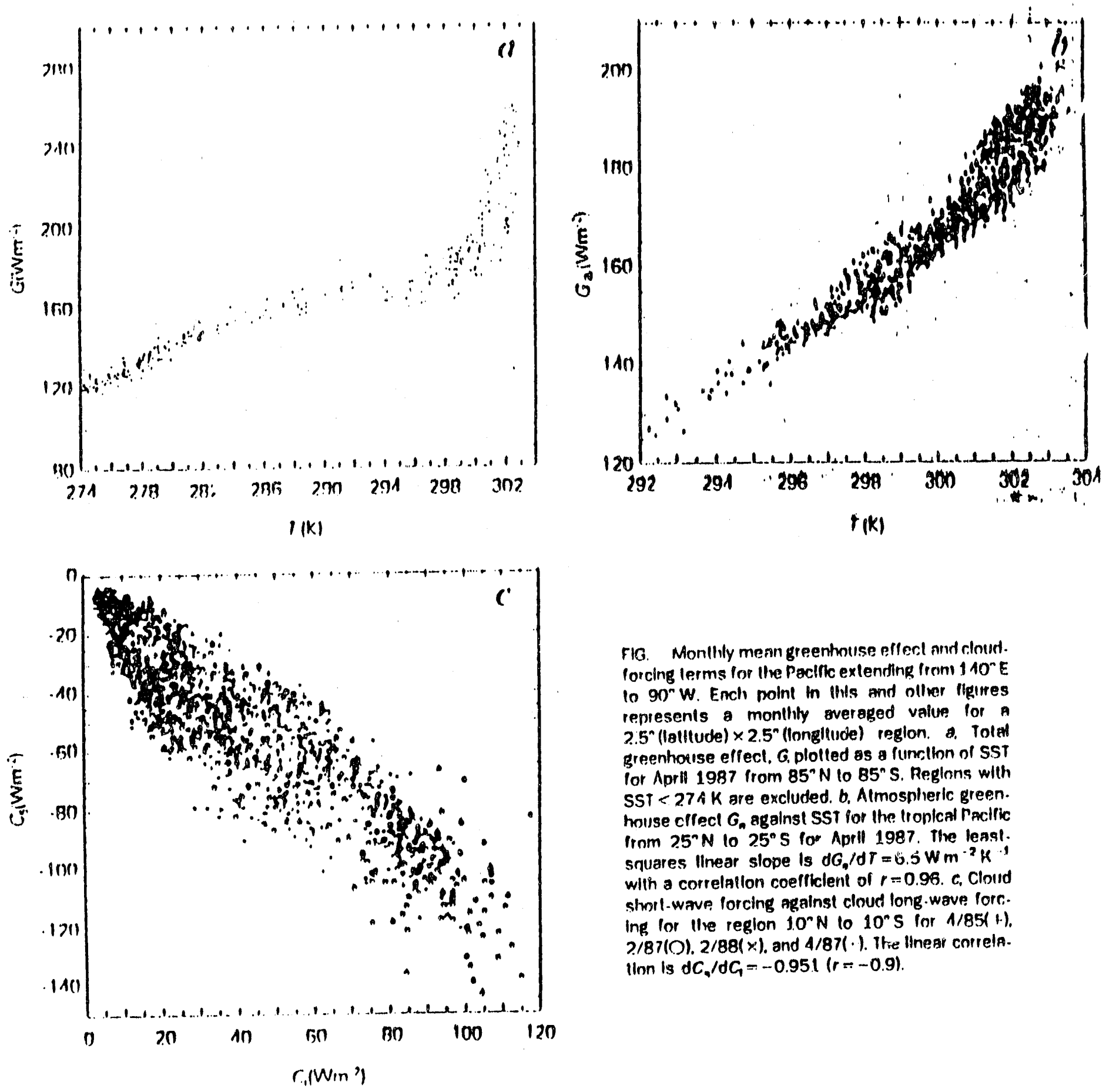

FIG. Monllily menn greentouse ellecl nut r.lout. forcing lerms for line Pacilic extending from $110^{-} \mathrm{E}$ to $90^{n} \mathrm{~W}$. Ench point in this and olluer Higitres represents a monllhy averaged value for a $2.5^{n}$ (lallude) $\times 2.5^{n}$ (longllude) region. a. Tolal greenhouse effect, G. plotted as a funclion of SST lor Aprlt 1987 from $85^{n} N$ to $85^{n} S$. Reglons with SST $<27 A \mathrm{~K}$ are excluded. $b$. Almospheric green. muse clfect $G_{n}$ agalnst SST for the lionical Pacilic Irnm $25^{\circ} \mathrm{N} 1025^{\circ} \mathrm{S}$ for April 1987. The least. squares linear slope is $\mathrm{d} G_{q} / \mathrm{d} T=6.5 \mathrm{Wm}^{-2} \mathrm{~K}^{-1}$ with a correlation coefficlent of $r=0.96$. $c$. Cloud shorl-wave forcing agalnst cloud long wave lore. ing for the reglon $10^{n} \mathrm{~N}$ to $10^{n} \mathrm{~S}$ ior $1 / 85(\mathrm{H})$. 2/87(O), 2/88( $\times)$, and $4 / 87(\cdot)$. The linear correla. linn is $\mathrm{d} C_{4} / \mathrm{d} C_{1}=-0.951(r=-0.9)$.

FIGURE 4a: ERBE Data

Source: Ramanathan \& Collins (1991). 

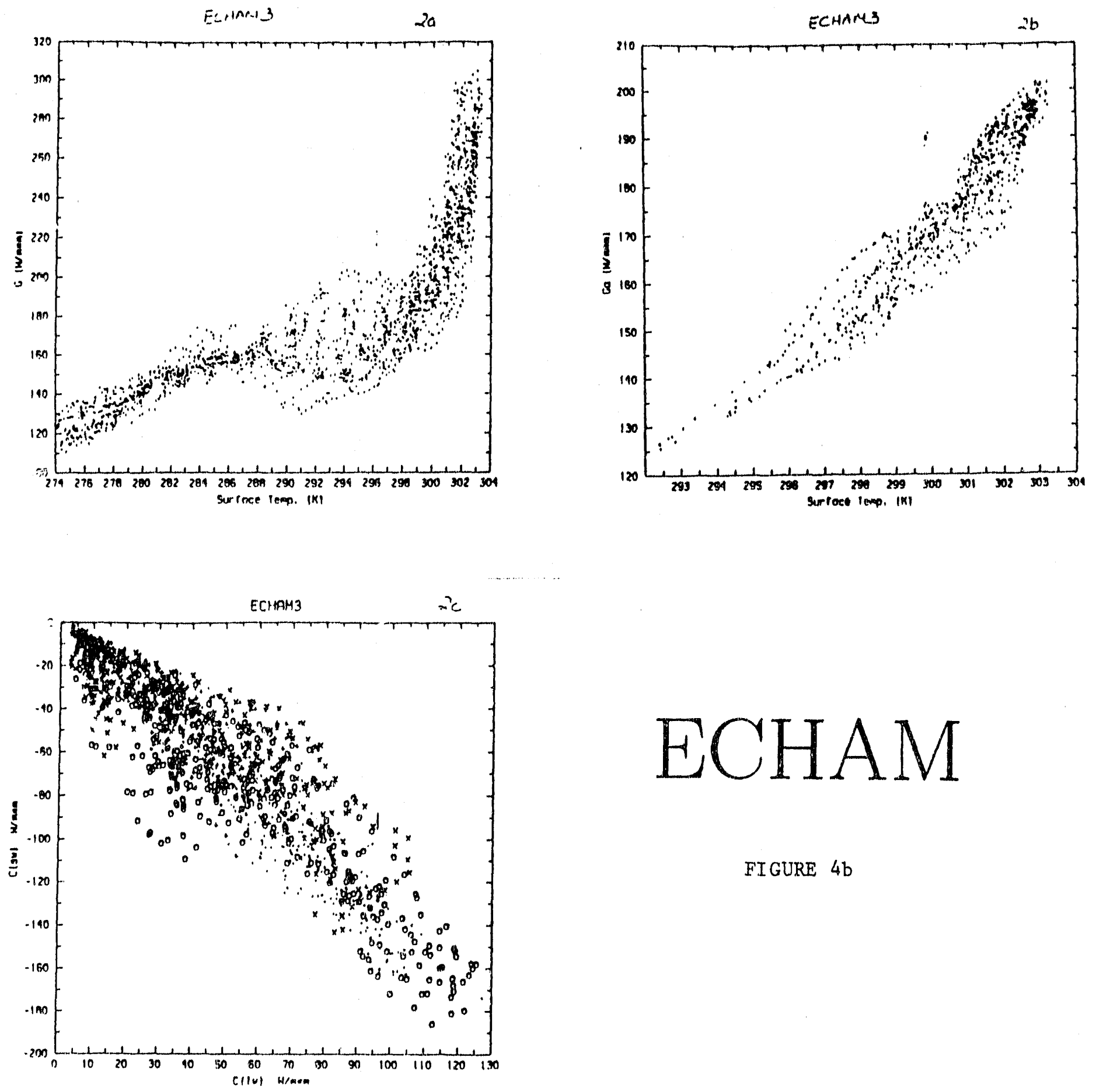

FIGURE $4 \mathrm{~b}$ 
FIGURE 5: Changes in SST and radiation fluxes during El-Niño of 1987.

Figure 5a (first image): Observed changes between April 1985 and April 1987. Top left is change in SST. Top right is change in atmospheric greenhouse effect. Bottom left is change in shortwave cloud forcing. Bottom right is change in longwave cloud forcing.

Figure $5 b$ (second image): Same as Figure $5 a$, but for the computed changes by the model ECHAM. 


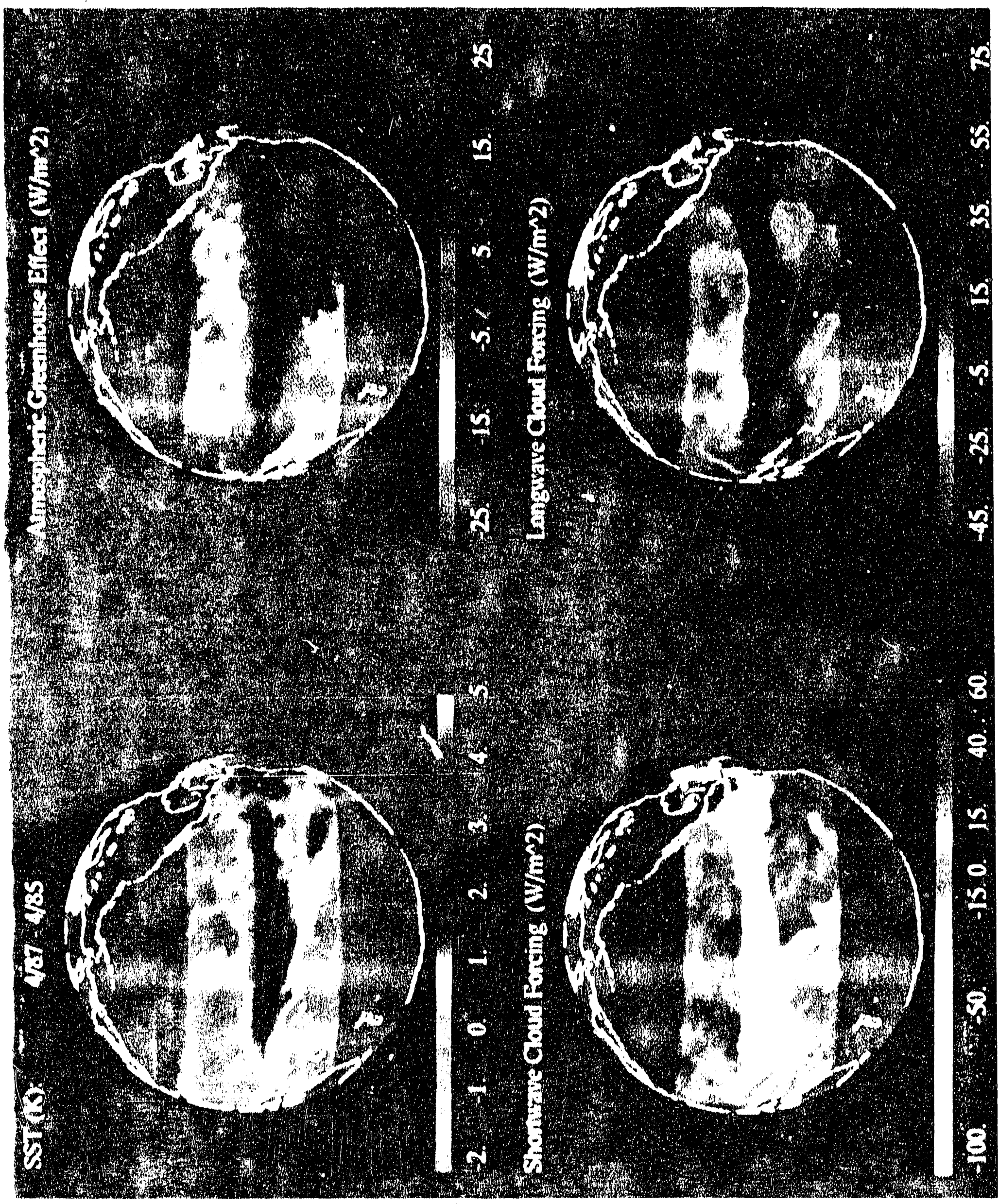




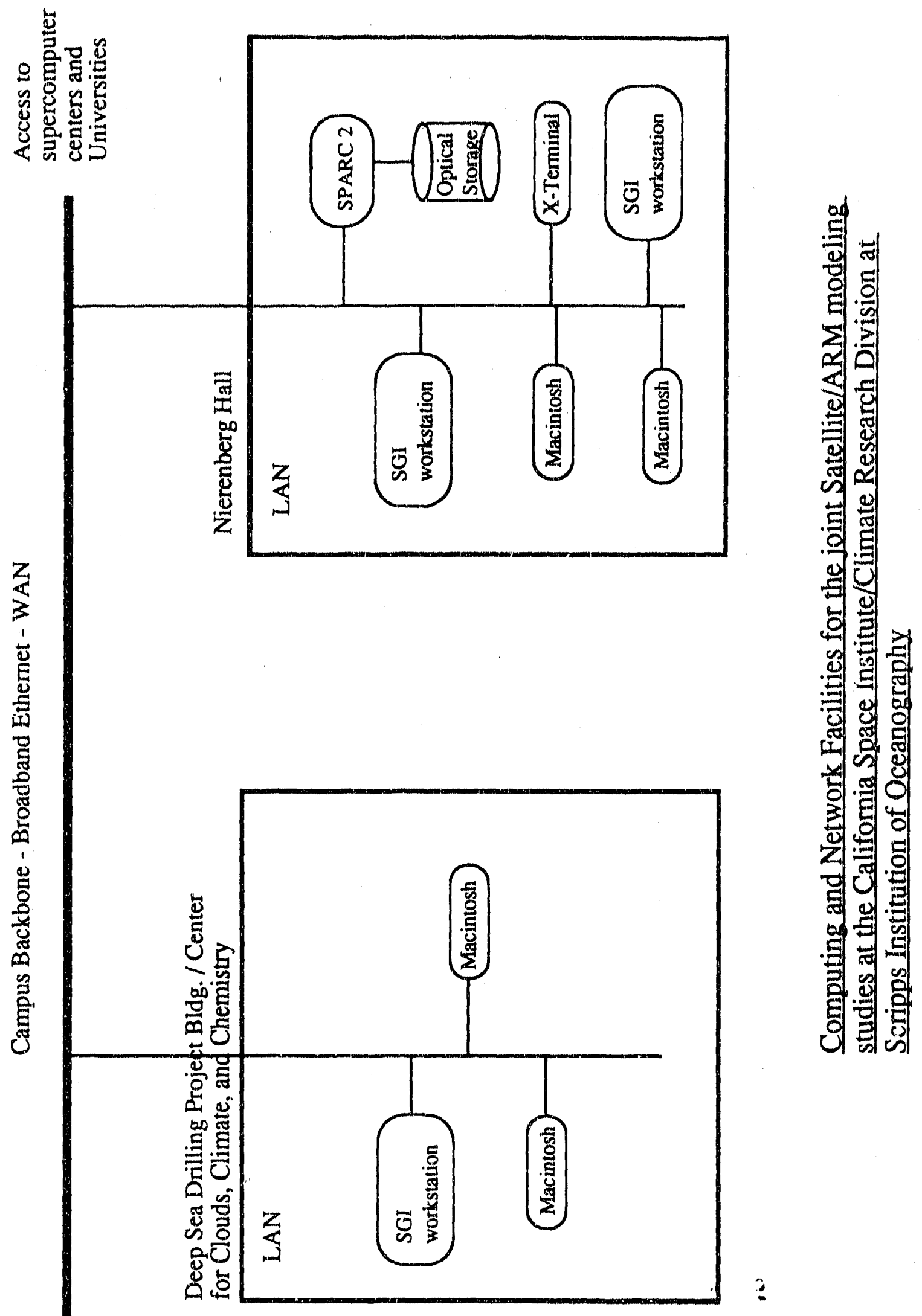

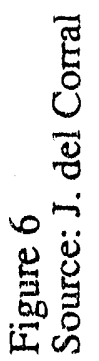




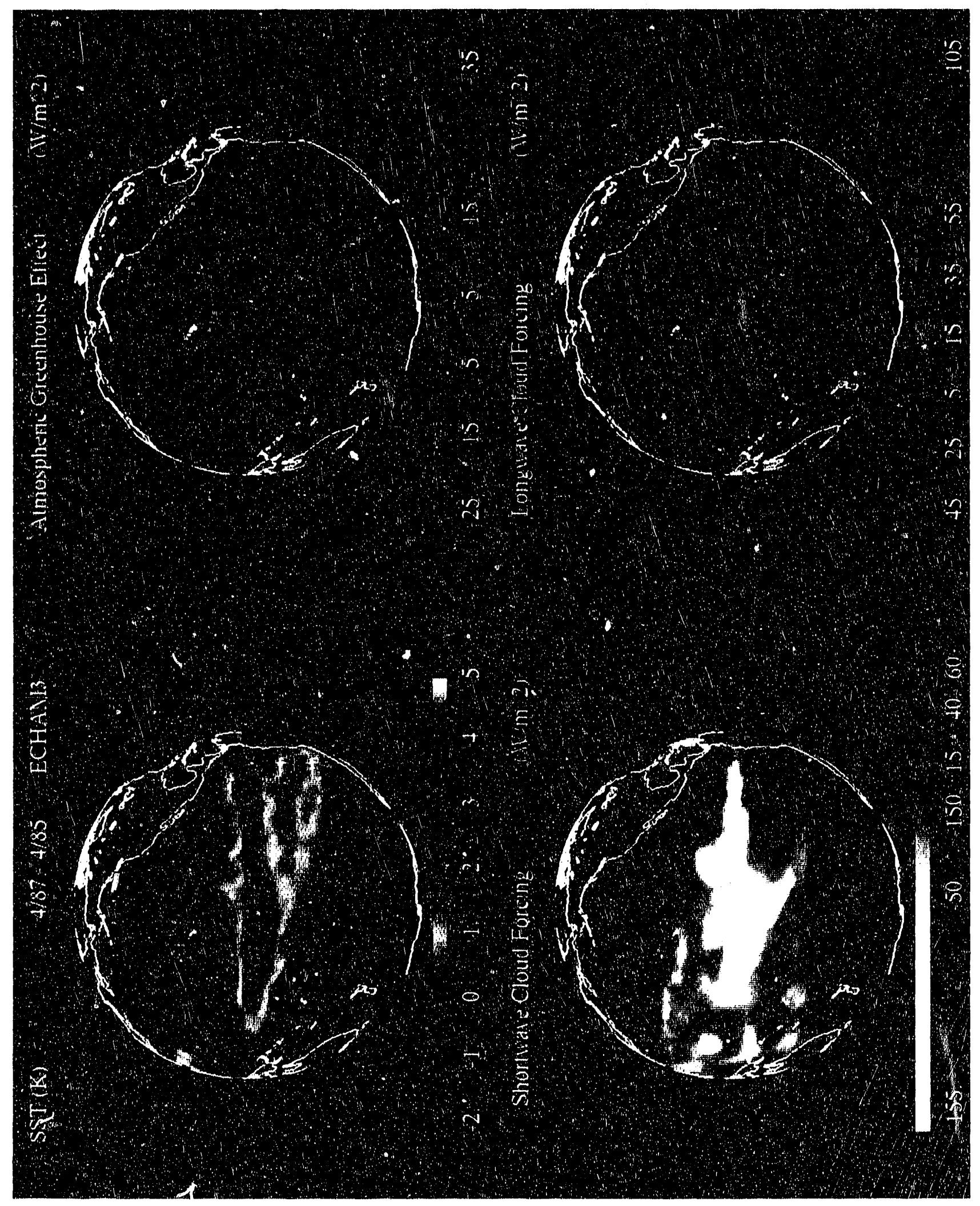



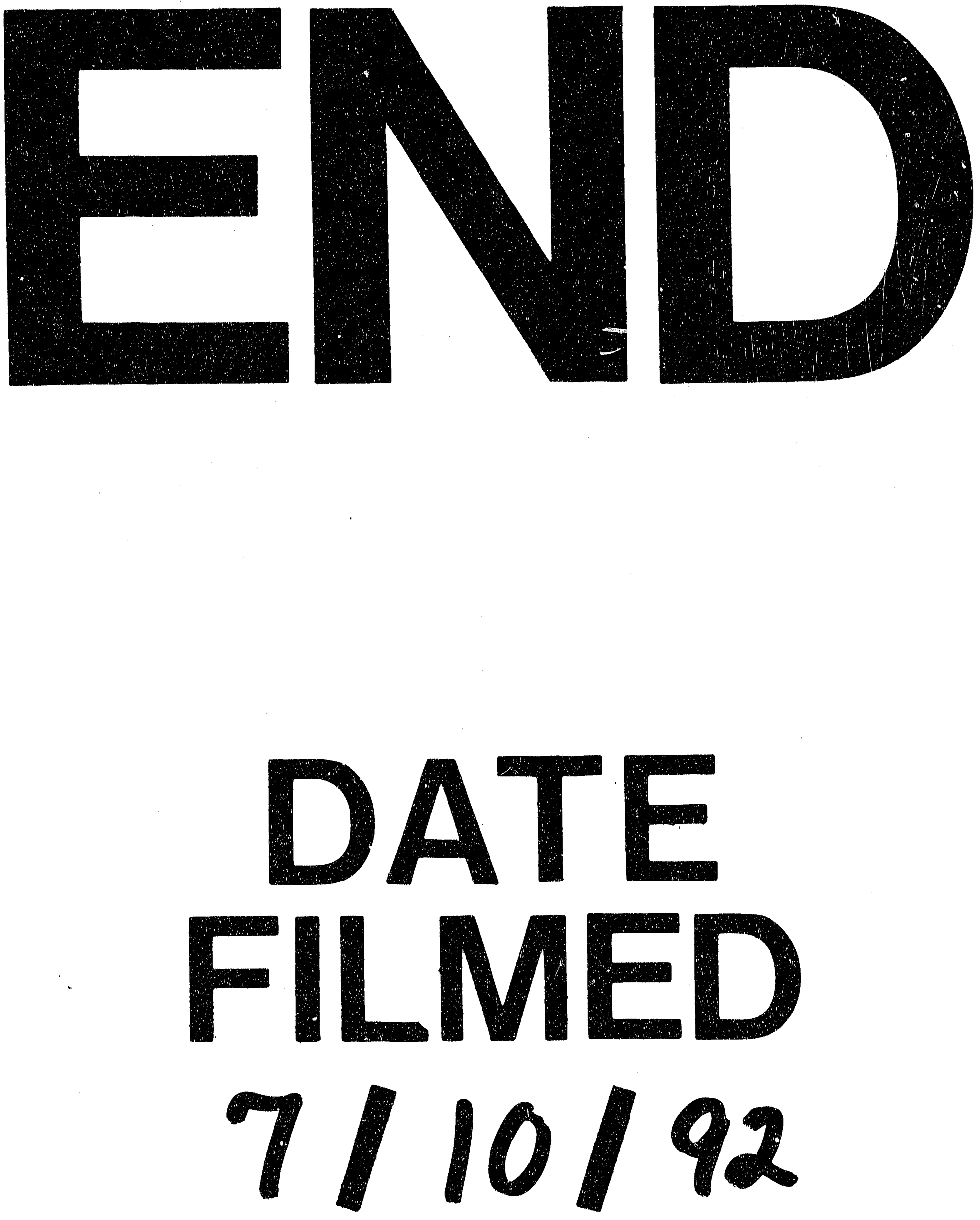
